\title{
NIMBY and mechanism design under different constitutional constraints*
}

\author{
Martin Besfamille ${ }^{\dagger} \quad$ Jean-Marie Lozachmeur ${ }^{\ddagger}$
}

November 19, 2008

\begin{abstract}
This paper analyses, in a simple two-region model, the undertaking of noxious facilities when the central government has limited prerogatives. The central government decides whether to construct a noxious facility in one of the regions, and how to finance it. We study this problem under both full and asymmetric information on the damage caused by the noxious facility in the host region. We particularly emphasize the role of the central government prerogatives on the optimal allocations. We finally discuss our results with respect to the previous literature on NIMBY and argue that taking into account these limited prerogatives is indeed important.

Keywords: Noxious Facilities - NIMBY - Asymmetric information - Mechanism Design - Constitutional constraints

JEL Codes: D82 - H77
\end{abstract}

${ }^{*}$ This work builds on a previous paper that circulated under the title "Construction of facilities under asymmetric information: do constitutional constraints matter?" (CORE Discussion Paper 2002/42). We would like to thank the editor J. Wilson, an anonymous referee, S. Blomquist, V. Chari, J. Crémer, J. Hendricks, H. Hopenhayn, N. Ireland, J.-J. Laffont, P. Legros, B. Lockwood, A. Malik, A. Manelli, M. Marchand, D. Martimort, F. Menezes, R. Myerson, S. Nandeibam, Z. Neeman, P. Pestieau, J. Pouyet, P. Rey, K. Scharf, I. Werning, S. Wilkie, conference participants at IIPF (2001), LAMES (2002), LACEA (2002), APET (2003) and, seminar participants at Banco Central del Uruguay, Fundaçao Getulio Vargas, IAE, University of Warwick, Université de Liège, Universidad de San Andrés, Universidad Nacional de La Plata and Universidad Torcuato Di Tella for their helpful comments and suggestions. We thank initial financial support from the Communauté française de Belgique (ARC 98/03-221). M. Besfamille also acknowledges financial support from FNRS (Grant V 6/5/6 - MJ. 3232) and from Maison des Sciences de l'Homme de Paris (Hermes Grant).

${ }^{\dagger}$ Department of Economics, Universidad Torcuato Di Tella. E-mail: mbesfamille@utdt.edu

†Toulouse School of Economics (CNRS-GREMAQ and IDEI). E-mail: jean-marie.lozachmeur@univtlse1.fr 


\section{Introduction}

For most jurisdictional authorities, the construction of noxious facilities [e.g. airports, prisons, waste disposals] is usually problematic. Such facilities produce important benefits for the jurisdiction as a whole, while their costs are mainly concentrated in the host locality. Therefore, localities oppose to host noxious facilities, generating what is commonly known as the 'NIMBY' syndrome. ${ }^{1}$

An important strand of literature analyzes NIMBY as a problem of asymmetric information, assuming that localities possess more information than the jurisdictional authority. Under these circumstances, localities use their private information strategically to induce the jurisdictional authority to make a decision that favors them. ${ }^{2}$ This literature presents different mechanisms to fill this informational gap, like auctions, insurance devices and incentivecompatible monetary compensations.

We depart from this previous literature in the following important aspect: the prerogatives that jurisdictional authorities have when they decide upon the construction of a noxious facility. The previous literature adopts extreme assumptions concerning these prerogatives. On the one hand, some contributions assume that the jurisdictional authority is obliged to respect the localities' status quo (i.e. their welfare when the noxious facility is not constructed) or their autonomy (i.e. the level of welfare when each locality constructs the noxious facility by itself). Formally, the mechanisms designed to elicit the localities's private information should include some kind of ex-ante, interim or ex-post 'participation constraint'. On the other hand, other authors assume that the jurisdictional authority is endowed with unlimited powers to implement its preferred policy. Under this different institutional framework, the mechanisms need to verify no participation constraint.

In fact, these assumptions are not adequate for a general analysis of NIMBY. Although jurisdictional authorities do have prerogatives regarding the construction of noxious facilities, these prerogatives are usually limited. On the one hand, a jurisdictional authority is not always obliged to respect the status quo of all localities ${ }^{3}$; it can indeed force them to participate in the siting procedure. But, on the other hand, a jurisdictional authority can not impose any decision to the host locality. The former is often constitutionally compelled to ensure the latter with a minimum level of welfare. The following example concerning a federal noxious facility in the U.S.A. illustrates these assertions. Provided the choice of the site has followed the legal procedures, the U.S. Congress has the last word about the construction of a federal noxious facility, no matter the reaction at the state or at the local level. ${ }^{4}$ Moreover, if the land on which the noxious facility will sit is not owned by the Federal Government (but, for example, by a state or a locality), the Federal Government can exercise

\footnotetext{
${ }^{1}$ NIMBY is the acronym of the expression 'Not In My Back Yard'.

${ }^{2}$ Goetze (1982) pointed that, with respect to waste disposals, host localities express fears of risk that may be exaggerated and strategically motivated.

${ }^{3}$ When spillovers are an issue, jurisdictional authorities can even prohibit localities to construct their own facility, going beyond their autonomy. See footnote 12 .

${ }^{4}$ On July 2002, the U.S. Congress approved the construction of a deep, mined geologic repository for high-level radioactive waste at Yucca Mountain, despite the Nevadans were strongly against the project.
} 
the power of 'eminent domain' to expropriate it. But there is a limit to such power. When intergovernmental takings occur, federal courts require the Federal Government to compel to the Takings Clause of the Fifth Amendment to the U.S. Constitution and so to compensate the owner for its taken land. ${ }^{5}$

The purpose of this paper is precisely to fill this gap in the literature ${ }^{6}$ and find the optimal mechanism to construct a noxious facility, integrating into the analysis the limited prerogatives of jurisdictional authorities. We present a simple model of a country, with two equally wealthy regions, each ruled by a local authority. The central government has to decide whether to construct a noxious facility in one of the regions and, if so, how to finance it. If the facility is undertaken, it causes a damage in the host region but generates a benefit in the other region. When making its decision, the central government is constitutionally constrained to leave to each region the same exogenous minimal level of welfare. The main novelty of this paper is that this minimal level of welfare can be below the status quo but cannot reach $-\infty$, which is the value that characterizes a jurisdictional authority with unlimited powers. We assimilate this minimal level of welfare to a 'constitutional constraint'. Furthermore, we assume that the central government does not observe the damage caused by the noxious facility. This value is private information of the host region. To deal with this informational gap, the central government designs an incentive-compatible mechanism that, conditional on the reported damage, specifies whether the facility will be constructed and a balanced schedule of transfers to the regions.

The most important results of the paper are as follows. Under full information, there is an endogenous threshold such that, if the value of the damage is below (above) this threshold, the noxious facility is optimally constructed (not constructed). This threshold depends upon the benefit generated in the other region and also upon how stringent the constitutional constraint is. We also find the optimal full information cost-sharing rule when the noxious facility is constructed. As expected, the higher is the damage, the lower is the financial participation of the host region in the construction's cost.

Under asymmetric information, the central government faces an evident incentive problem. The host region wishes to exaggerate its damage, for two different reasons: 1) to contribute less to the construction cost or to obtain an undue compensation or 2) to induce the central government to not undertake the noxious facility. This last misbehavior is precisely the 'opposition to siting' described by the NIMBY literature.

We completely characterize the optimal mechanism. As usual, in order to attenuate the stakes for misreport, the central government distorts construction decisions and transfers, with respect to the full information ones. Again, we find an endogenous threshold for the damage, lower than the full information one, under which the noxious facility is constructed.

\footnotetext{
${ }^{5}$ These assertions concerning limited prerogatives that governments have also apply to other areas of public policy. Taxation is perhaps the paradigmatic case. Almost all constitutions endow governments to tax their population. But this power is usually (constitutionally or judicially) limited: taxes cannot be 'unfair' or 'confiscatory'. See Darby (1990).

${ }^{6}$ Some authors, like Rob (1989) and Minehart and Neeman (2002), recognized that jurisdictional authorities have sometimes the power to force localities to participate in the siting/constructing procedure. But their formal models do not incorporate this issue.
} 
Hence, for each constitutional constraint, we identify facilities that are optimally not constructed, whereas they should have been undertaken under full information. We also show that, provided the central government has the power to do so, it is optimal to tax the host region when the noxious facility should not be undertaken. Therefore, adopting this more realistic assumption of limited prerogatives also implies that it is necessary to discuss about the restrictions on transfers that the central government can impose to both regions. Finally, we prove that assuming the same minimal level of welfare for both regions is without any loss of generality.

The layout of the remainder of the paper is as follows. In the next section we present the model. Section 3 analyzes the full information benchmark. In Section 4, we study the problem under asymmetric information. In Section 5 we compare our results to the existing literature. Finally, Section 6 concludes. All proofs are in the Appendix.

\section{The model}

In a country, there are two regions $i=H, R$. Each region is ruled by a local authority. On the top of both local authorities, a central government decides whether to construct a facility of a given size in region $H$. This construction decision is formalized as an index variable $\delta$, where $\delta=1$ if the facility is constructed and 0 otherwise.

If the facility is constructed, it produces a strictly positive benefit $b$ in region $R$ but also causes a damage $d$ to the host region $H$. These two values clearly characterize the facility as being noxious. The damage $d$ is a random variable, independent of $b$, drawn from a differentiable cumulative distribution function (cdf) $F(d)$, with support in the interval $[0, D]$, where $D>0$. We also assume continuous differentiability of this cdf and we denote its density by $f(d)$. The noxious facility costs $c$, which is common knowledge. If it is undertaken, the central government bears this cost.

The local authority is the representative agent of the region. For the sake of simplicity, we assume that both regions have the same endowment $\omega$. Each region consumes a private good in quantity $q$. They derive the same utility from the consumption of this good. This utility is formalized as a strictly increasing and concave function $u(q)$, with $u(0)=0$.

The central government designs a scheme of transfers $t_{i}^{\delta}$. When $t_{i}^{\delta} \geq 0$, the region $i$ is taxed; when $t_{i}^{\delta}<0$, the region $i$ is subsidized. Therefore, taking into account each region's budget constraint $q_{i}=\omega-t_{i}^{\delta}$, ex-post regional levels of welfare $\operatorname{are}^{7}$

$$
\left\{\begin{array}{l}
W_{H}=u\left(\omega-t_{H}^{\delta}\right)-\delta d \\
W_{R}=u\left(\omega-t_{R}^{\delta}\right)+\delta b
\end{array}\right.
$$

The goal of the central government is to choose an allocation $\left(\delta, t_{H}^{\delta}, t_{R}^{\delta}\right)$ in order to maximize an utilitarian social welfare $\mathcal{W}=W_{H}+W_{R}$, subject to the weakly budget balance constraint

\footnotetext{
${ }^{7}$ We assume that regional endowments $\omega$ are such that we do not need to impose limited liability constraints.
} 
$\sum_{i} t_{i}^{\delta} \geq \delta c$. Note that the region's utility is separable between the private and the public good. In spite of being quasi-linear in the noxious facility's damage or benefit, welfare is non-transferable because the function $u(\mathrm{)})$ is non linear. As a consequence, the central government care about the distribution of after-tax income between the two regions.

As we mentioned above, the central government controls the construction decision $\delta$. On the one hand, it can impose the construction of the noxious facility, even if region $H$ suffers the damage. On the other hand, it can decide the opposite, even if the benefit $b$ is so high that region $R$ wants its construction. Although this seems to be a "command-andcontrol' economy, the central government faces an important constraint on the allocations $\left(\delta, t_{H}^{\delta}, t_{R}^{\delta}\right)$ it wishes to implement. This restriction imposes the central government to leave to each region $i$ a minimal level of ex-post utility $k \in]-\infty, u(\omega)]$ Formally, this restriction is $W_{i} \geq k, i \in\{H, R\}$ and is denoted by $C C_{i}$. We call this constraint $C C_{i}$ a 'constitutional constraint' because it is usually the Constitution that limits the prerogatives of the central government.

The upper bound $u(\omega)$ reflects the status quo (i.e. the level of welfare each region attains if the noxious facility is not constructed) and ensures only Pareto improving constructions. ${ }^{8}$ The lowest bound $-\infty$ corresponds to the case of a non-constrained central government, where every project that have a high enough value for the country as a whole will be undertaken. As we have explained in the introduction, the most interesting and realistic case is when $k \in]-\infty, u(\omega)[$ : the central government has limited prerogatives. Although it can construct a noxious facility that causes a damage in region $H$, the final allocation cannot be too detrimental for this region. If the central government insists in imposing to region $H$ an allocation that leaves to it a welfare level below $k$, region $H$ can obtain the noxious facility's shutdown. ${ }^{9}$

The assumptions of the model deserve some comments. First, our paper does not deal with the localization of the facility. Although this is a crucial problem for some kind of facilities (e.g. prisons), there are many others for which their localization is not an issue (e.g. nuclear waste disposals, dams). For such facilities, there often exists only one locality that has, for example, the appropriate hydrological and geological characteristics to become the host. Second, the construction decision $\delta$ is discrete. We could have assumed $\delta \in[0,1]$ and thus considered it as the probability of constructing the noxious facility. But, although this generalization changes some results (specially those concerning the optimal transfers under asymmetric information), it does not improve substantially the understanding of the impact

\footnotetext{
${ }^{8}$ Here, ensuring the status quo is formally equivalent to the 'respect for autonomy', as set by O'Sullivan (1993), Klibanoff and Morduch (1995) and Minehart and Neeman (2002). In those models, in case of no agreement with the central government, each region is free to construct its own facility. First, in our model, no region will voluntarily undertake the noxious facility. Second, the respect for the autonomy is not always a realistic assumption for analyzing provision of public goods within a federation. For example, in the USA, no state can construct dams over interstate rivers without the approval of the Federal Energy Regulatory Commission (Federal Power Act, 16 USC 797).

${ }^{9}$ One can also interpret our constitutional constraint as a reduced form of a secession-proof constraint like $W_{i} \geq(1-\kappa) u(\omega) \equiv k$ where $\kappa \in[0, \infty[$ represents the cost of secession. In this case, the central government has some degree of freedom to implement its policy because the secession is costly for regions. We thank B. Lockwood for suggesting this interpretation to us.
} 
of the different constitutional constraints upon the optimal allocations. Third, as the benefit $b$ is known, we rule out issues of revelation of multidimensional asymmetric information from our model. The reason for doing that is to simplify at most the model to be able to characterize allocations when the central government has limited prerogatives. Fourth, although it may seem odd to assume the same level of minimal welfare for both regions, we show in Section 4.1 that this assumption is without any loss of generality. Finally, by considering $k$ exogenous, we do not seek to explain where this value comes from. ${ }^{10}$ Our goal is simply, as we have just mentioned above, to see what can be achieved given different constitutional constraints (i.e. different values of $k$ ) on the optimal allocations.

\section{$3 \quad$ Full information}

As a benchmark, we present the full information allocations $\left\{\delta^{*}, t_{H}^{1 *}, t_{R}^{1 *}\right\}$. When the central government observes $b$ and $d$, optimal transfers verify $\sum_{i} t_{i}^{1}=c$ and $t_{i}^{0}=0$. These allocations appear in Figures 1(a) and 1(b), where each point $(b, d)$ represents a noxious facility.

Insert Figure 1(a) here

Insert Figure 1(b) here

In both figures, the bold curve depicts the frontier $d^{*}$, above which no facility is constructed. In this area, each region has the status quo level of welfare $u(\omega)$. Below $d^{*}$, each noxious facility is optimally constructed. There, the optimal transfers also depend upon how stringent the constitutional constraint is. In Figure 1(a), when $k$ is 'relatively' high, the prerogatives of the central government are not so broad and thus the constitutional constraint $C C_{H}$ always binds. In this case the transfer $t_{H}^{1 *}$ is simply given by the binding constitutional constraint, and the other transfer $t_{R}^{1 *}$, by the central government's budget constraint. Region $H$ pays less than $c / 2$ and its contribution decreases with the damage $d$. Therefore, for relatively high values of the damage, region $H$ can even be compensated for hosting the noxious facility.

In Figure 1(b), when $k$ is 'relatively' low, the central government has more power and two different schedules of transfers emerge. If the damage is relatively low, below $u(\omega-c / 2)-$ $k$, the constitutional constraint $C C_{H}$ does not bind. Consequently, marginal utilities of consumption (and thus transfers) are equalized between the two regions. But if the damage is relatively high, above $u(\omega-c / 2)-k$, transfers are the same than in the previous figure.

Looking at both figures, we can see how the frontier $d^{*}$ varies with $k$. In the first figure, the frontier $d^{*}$ is increasing and concave in $b$. In the second figure, the shape of the frontier $d^{*}$ is first linear with $b$, then it becomes concave. When $k$ decreases, the size of the linear part

\footnotetext{
${ }^{10}$ In a similar framework, Neeman (1999) gives a rationale for values of $k<u(\omega)$. See Section 5 .
} 
increases. The limit case is when $k \rightarrow-\infty$ : the central government faces no constitutional constraint. The frontier becomes a straight line under which each facility is constructed and each region shares equally the cost $c$ : equalization of marginal utilities of consumption always applies. Summing up, the less stringent the constitutional constraints is, the more facilities will be constructed, i.e. $d^{*}(b, k)<d^{*}\left(b, k^{\prime}\right)$ for any $k>k^{\prime}$.

\section{Asymmetric information}

Now, we assume that the central government observes $b^{11}$ but only knows the distribution $F(d)$ over $[0, D]$. In fact, the damage $d$ is the local authority's private information. This last assumption also deserves some comments. First, it is a short-cut for a more general model, where the noxious facility generates two types of damages: i) damages to common interests $d_{1}$ (e.g. environmental risks) and, ii) damages to individual interests $d_{2}$ [see Wolsink (1994)]. In such a model, a central agency with technical expertise could know the value of $d_{1}$ but only the local authority of region $H$ is able to observe $d_{2}$. For the sake of simplicity, we set $d=d_{2}$. Second, the informational superiority of the local authority can be justified, as in Cremer, Estache and Seabright (1995) and Bucovetsky, Marchand and Pestieau (1998), on political economy grounds. To win elections, politicians need to know the preferences of their voters. In the context of our model, this implies that local politicians have more incentives to learn about $d$ than national politicians because the latter have to deal with a larger set of voters.

In order to focus on the most general case, we only consider values of $b$ and $D$ such that $D>>d^{*}$ for $k \rightarrow-\infty$. We characterize the optimal allocations adopting a mechanism-design approach. In our setting, the Revelation Principle applies. The region $H$ reports its damage $d$ and the central government commits to implement the allocations $\left\{\delta(d), t_{H}^{\delta(d)}(d), t_{R}^{\delta(d)}(d)\right\}$. Under asymmetric information, the optimal allocations solve the program $\mathcal{P}$

$$
\mathcal{P} \begin{cases}\underset{\delta(d), t_{H}^{\delta(d)}(d), t_{R}^{\delta(d)}(d)}{\operatorname{Max}} \int_{0}^{D}\left[u\left(\omega-t_{H}^{\delta(d)}(d)\right)+u\left(\omega-t_{R}^{\delta(d)}(d)\right)+\delta(d) \cdot(b-d)\right] d F(d) \\ \text { subject to } \\ u\left(\omega-t_{H}^{\delta(d)}(d)\right)-\delta(d) \cdot d \geq k \\ u\left(\omega-t_{R}^{\delta(d)}(d)\right)+\delta(d) \cdot b \geq k & \left(C C_{H}\right) \\ \sum_{i} t_{i}^{\delta(d)}(d) \geq \delta(d) \cdot c & \left(B C_{R}\right) \\ u\left(\omega-t_{H}^{\delta(d)}(d)\right)-\delta(d) \cdot d \geq u\left(\omega-t_{H}^{\delta\left(d^{\prime}\right)}\left(d^{\prime}\right)\right)-\delta\left(d^{\prime}\right) . d \quad \forall d, d^{\prime} \in[0, D] & \left(I C_{H}\right)\end{cases}
$$

where $\left(C C_{H}\right)$ and $\left(C C_{R}\right)$ are the constitutional constraints, and $(B)$, the central government's budget constraint. The new constraints $\left(I C_{H}\right)$ form the set of incentive-compatibility

\footnotetext{
${ }^{11}$ In spite of that, the value of $b$ will play an important role in the implementation game.
} 
constraints. Each of these constraints prevents a region $H$ with damage $d$ to pretend to be a region with a different damage $d^{\prime}$. The following lemma presents some important intermediary results.

\section{Lemma 1}

1. Let $d \neq d^{\prime}$. If $\delta(d)=\delta\left(d^{\prime}\right)=1$, then $t_{H}^{\delta(d)}(d)=t_{H}^{\delta\left(d^{\prime}\right)}\left(d^{\prime}\right)$.

2. If $d<d^{\prime}$, then $\delta(d) \geq \delta\left(d^{\prime}\right)$.

3. There exists a unique threshold $\widehat{d}$ such that if $d \leq \widehat{d}, \delta(d)=1$ and, if $d>\widehat{d}, \delta(d)=0$.

4. At the optimum, $\sum_{i} t_{i}^{1}=c$ and $\sum_{i} t_{i}^{0}=0$.

5. The constraint $u\left(\omega-t_{H}^{1}\right)-d \geq k$ is redundant.

The first statement of the lemma shows that incentive-compatibility imposes a huge constraint on transfers: for any pair of reports that yields the same construction decision $\delta$, the corresponding transfers must be the same. ${ }^{12}$ Therefore, from now on, let $t_{i}^{1}$ and $t_{i}^{0}$ denote transfers when the noxious facility is constructed and not constructed, respectively. The second and the third statements characterize the optimal construction decision: $\delta$ is non-increasing in $d$ (monotonicity result) and, at $d=\widehat{d}, \delta$ jumps downwardly to 0 . Hence $\widehat{d}$ is the highest damage for which the noxious facility is constructed. The fourth statement of the lemma says that, at the optimum, all budget constraints bind. Finally, the last statement shows one constraint that is redundant at the optimum. Clearly, Lemma 1 simplifies the problem $P$. In the Appendix, we solve the simpler problem using the Lagrangian technique. In the following proposition, we only present the results that we analyze afterwards.

Proposition 1 Under asymmetric information on the damage d, the optimal allocations are as follows.

1. When $d \leq \widehat{d}, \delta=1$ and $t_{H}^{1}<t_{R}^{1}=c-t_{H}^{1}$. When $d>\widehat{d}, \delta=0$ and $t_{H}^{0} \geq 0$.

2. The threshold $\widehat{d}$ and the transfers $t_{H}^{1}$ and $t_{H}^{0}$ satisfy $u\left(\omega-t_{H}^{1}\right)-\widehat{d}=u\left(\omega-t_{H}^{0}\right)$.

3. The threshold $\widehat{d}$ satisfies $\widehat{d}<d^{*}$.

4. There exists a threshold $\widehat{k}$ such that:

(a) when $k \geq \widehat{k}, \widehat{d}$ decreases with $k$ and $u\left(\omega-t_{H}^{0}\right)=k$.

(b) when $k<\widehat{k}, t_{H}^{0}$ and $\widehat{d}$ do not depend upon $k$ and $u\left(\omega-t_{H}^{0}\right)>k$.

\footnotetext{
${ }^{12}$ This is the unique result that does not hold if $\delta \in[0,1]$.
} 
First, let us explain the first two statements of the proposition. On the one hand, we know from Lemma 1 that the noxious facility is constructed in any region $H$ with damage $d \leq \widehat{d}$. To fulfill the incentive-compatibility constraint, the region $H$ with damage $\widehat{d}$ should face the incentive transfer $t_{H}^{1}$. This transfer is designed to induce this particular region $H$ not to provoke the shutdown of the noxious facility by exaggerating its damage. This misbehavior is precisely the NIMBY syndrome. Moreover, as we also know from Lemma 1, every region $H$ with damage $d<\widehat{d}$ must face the same transfer $t_{H}^{1}$, so that they have no incentives to report $\widehat{d}$ and thus to contribute less to the construction of the noxious facility. This means that all regions $H$ with $d<\widehat{d}$ receive a strictly positive informational rent. This informational rent is not evaluated with respect to the status quo but to the shutdown of the noxious facility. As usual, this informational rent is costly. The reason is the following. As the region $R$ supports more of the construction cost, the difference in transfers generates a welfare cost due to the concavity of the utility function $u()$. To attenuate this welfare cost, the incentive-compatibility constraint binds. On the other hand, the noxious facility is not undertaken in regions $H$ with damage $d>\widehat{d}$. In this case, these regions pay the same tax $t_{H}^{0} \geq 0$ (strictly positive as soon as $k<u(\omega)$ ), as Lemma 1 shows. This tax reflects the tradeoff between the welfare gain from relaxing the (binding) incentive-compatibility constraint (due to a decrease in the informational rent to be left to all regions $H$ with damage $d<\widehat{d}$ ) and the welfare cost (due to a higher inequality between region $H$ and $R$ when the noxious facility is not constructed).

The third statement of the proposition affirms that under asymmetric information on the damage $d$, less noxious facilities are constructed than under full information. Now, the optimal value of $\widehat{d}$ is the result of the following trade-off. Consider a given threshold $d^{\prime}<d^{*}$ and increase it slightly to $d^{\prime \prime}$. On the one hand, expected welfare increases because more socially valuable noxious facilities will be constructed. But, on the other hand, by incentivecompatibility, the region $H$ with damage $d^{\prime \prime}$ faces a lower transfer than the one that faced the region $H$ with damage $d^{\prime}$. Hence all regions $H$ with damage $d \leq d^{\prime}$ face a lower transfer, which increases the contribution of the other region $R$ and thus the inequality.

The last statement of the proposition shows that, as under full information, the constitutional constraint $C C_{H}$ binds if $k$ is high enough, i.e. if the prerogatives of the central government are not so broad. Clearly, if the optimal transfer $t_{H}^{0}>0$ is relatively high, one hits the constitutional constraint $C C_{H}$. In this case, the threshold $\widehat{d}$ and the tax $t_{H}^{0}$ decrease with $k$, whereas the transfer $t_{H}^{1}$ goes in the opposite direction. When $k$ is below a threshold $\widehat{k}$, the constitutional constraint $C C_{H}$ ceases to bind and the values of $t_{H}^{0}, t_{H}^{1}$ and $\widehat{d}$ become independent of $k$.

These results enable us to fully understand the impact of the different constitutional constraints on the optimal allocations. When the government is compelled to respect the status quo in any region, no $\operatorname{tax} t_{H}^{0}$ can be imposed when the noxious facility is not constructed. Under this constitutional framework, the discussion about constraints on transfers $t_{H}^{0}$ is useless. But this is not always the case. When the government can go beyond the respect of the status quo, it is necessary to address the question whether taxes $t_{H}^{0}$ are allowed. If, according to Samuelson (1985), the government is not allowed to impose such taxes, the 
constitutional constraint does not play any role, even if $k<u(\omega)$. Indeed, an incentive compatible mechanism has to ensure the same welfare to the region $H$ with damage $\widehat{d}$ and to another host region with damage $d>\widehat{d}$. As for the latter $t_{H}^{0}=0$, the noxious facility is constructed provided the level of welfare is above the status quo level $u(\omega)$. But when the central government can tax a region $H$ when the noxious facility is not constructed, the former, using its prerogatives, should make use of this tax in order to relax the (binding) incentive-compatibility constraint.

\subsection{Optimal allocations with different constitutional constraints}

Until now, we have assumed that both regions were facing the same minimal level of expost utility $k$. Let's consider a more general problem where, instead of $k$, the rhs of each constitutional constraint $C C_{i}$ is replaced by $k_{i}$, for $i=H, R$. The following proposition affirms that, in fact, only $k_{H}$ matters in this case.

Proposition 2 Under asymmetric information on the damage d, the optimal allocations described in Lemma 1 and Proposition 1 fulfill the constitutional constraint $C C_{R}$, for any $\left.\left.k_{R} \in\right]-\infty, u(\omega)\right]$.

This result can be proved by simply inspection of Lemma 1 and Proposition 1. First, all statements of Lemma 1 are unaffected by the change mentioned above, except for the last, where $k$ is simply replaced by $k_{H}$. Similarly, no statement of Proposition 1 changes, except that in the fourth statement, $\hat{k}$ and $k$ are replaced by $\hat{k}_{H}$ and $k_{H}$. In other words, the optimal allocations only depend on the value of $k_{H}$. Do these optimal allocations fulfill the constitutional constraint $C C_{R}$, for any $\left.\left.k_{R} \in\right]-\infty, u(\omega)\right]$ ? The answer is yes. When $\delta=0$, the first statement of Proposition 1 affirms that region $R$ at least benefits from a subsidy. This means that its ex-post utility is strictly greater than the status quo level $u(\omega)$, so that $C C_{R}$ is fulfilled. When $\delta=1$, optimality implies that a noxious facility with damage $\hat{d}$ and benefit $b$ is constructed provided the social welfare is at least higher than when the project is not undertaken. Formally, this is equivalent to the following condition: $u\left(\omega-t_{H}^{1}\right)-\widehat{d}+u\left(\omega-t_{R}^{1}\right)+b-u\left(\omega-t_{H}^{0}\right)-u\left(\omega+t_{H}^{0}\right) \geq 0 .{ }^{13}$ Given that the incentive compatibility constraint $I C_{H}$ always binds, this condition boils down to: $u\left(\omega-t_{R}^{1}\right)+b \geq$ $u\left(\omega+t_{H}^{0}\right)$. In other words, the ex-post utility of region $R$ when the noxious facility is constructed should at least be higher than the one when it is not undertaken. Since in the latter case the ex-post utility is at least equal to the status quo level $u(\omega)$, the constitutional constraint $C C_{R}$ never binds when $\delta=1$. This proves that assuming $k_{H}=k_{R}=k$ previously was without any loss of generality.

\footnotetext{
${ }^{13}$ See equation (6) in the appendix.
} 


\section{Related literature}

Starting from Samuelson (1985), the contributions by Kleindorfer and Kunreuther (1986), Easterling and Kunreuther (1992), O'Sullivan (1993), Kleindorfer and Sertel (1994), Easterling and Kunreuther (1996), Pérez-Castrillo and Wettstein (2002), Minehart and Neeman (2002), Kim (2003) and Jean-Marie, Marchetti and Tidball (2004) present auction and compensation like mechanisms to circumvent the NIMBY syndrome for the localization of a noxious facility. Our model differ from these articles in two aspects. First, we do not analyze localization of a noxious facility; we only deal with opposition to sit it in a given region. Second, none of these articles consider forced participation into the mechanism as we do.

Of course, we are not the first to allow for forced participation or expropriation in mechanisms. The early literature on provision of public goods under asymmetric information (Vickrey-Clarke-Groves mechanisms, d'Aspremont and Gérard-Varet mechanisms, Green and Laffont (1979)) and more recently Makowski and Mezzetti (1994), Ledyard and Palfrey (1994) and Lescop (2003) among others "would permit confiscatory action [...] if there were no constitutional limits on the proposals that could be considered." (Tideman and Tullock, 1976). As the mechanisms analyzed in those articles are not ex-post individually rational, the social planner can impose negative transfers when the project is not done, as our central government does. But in those contributions negative transfers are unbounded, which is one of our main criticisms against the assumption of a jurisdictional authority with unlimited powers. In spite of that, our result regarding the optimality of taxing the host region when the noxious facility is not constructed is to be related to the transfers in the Vickrey-ClarkeGroves mechanisms. The main difference between these transfers and ours is the following: our taxes $t_{H}^{0}$ do not depend directly on the forgone benefit in region $R$. The relationship with this benefit $b$ is only indirect: $t_{H}^{0}$ has to verify $u\left(\omega-t_{H}^{1}\right)-\widehat{d}=u\left(\omega-t_{H}^{0}\right)$ and, from the first-order conditions of the problem $\mathcal{P}$, we know that the value of $\widehat{d}$ is related to $b$.

Our paper adopts the mechanism-design approach, as Rob (1989), Klibanoff and Morduch (1995), Waehrer (2003) and Lescop (2006). Rob (1989) finds the optimal mechanism that enables a polluting firm to elicit the private information of its nearby residents, information about their cost of suffering pollution. The optimal mechanism consists of a probability of installing the plant and a schedule of incentive compensations. As it is usual in these settings, inefficient outcomes emerge, as it is the case in our paper. Interestingly, at the end of his article, Rob (1989) presents a numerical example where the residents are taxed if the plant is not constructed. With this example, Rob (1989) shows that relaxing the ex-post individual rationality constraint for a group of residents improves welfare. But he did not go beyond that numerical example. Our model, which considers explicitly this possibility, confirms rigorously his conjecture and finds the optimal 'penalties' for the potential host region if the noxious facility is finally not constructed therein. Klibanoff and Morduch (1995) study

a federation of two regions that must decide on a project with spillovers under asymmetric information. The authors also formalize constitutional constraints but in a different way than we do because they endow the regions with the right to control the project decision. The authors characterize the optimal allocations and analyze the relationship between distortions and the size of the spillovers. But their article does not consider that centralized provision 
of public goods may occur in an institutional setting where the central government has constitutional prerogatives to implement policies that may not respect every region status quo or autonomy. In a general multidimensional framework, Waehrer (2003) characterizes the optimal mechanism to sit a noxious facility. In spite of assuming that localities can be excluded for the use of the noxious facility, he does not consider the possibility that these excluded localities could be taxed anyway.

Two articles discuss the importance of relaxing, in a non-trivial way, the usual participation constraint. Gradstein (1994) analyzes a model of provision of a discrete public good. The author studies different regimes, where the agents outside option (interim and ex-post ) adopt other values than the zero-utility status quo and, like our approach, are bounded from below. But his results are less general than our findings because he assumes that it is always optimal to provide the public good, whereas we endogenize this decision. ${ }^{14}$ Neeman (1999) shows that efficient arrangements can be obtained, even under asymmetric information, when the structure of property rights is designed appropriately. This means, in a setting similar to Rob (1989), that it may be optimal to give to the polluting firm the right to pollute a given amount, which goes against (what is usually considered) the status quo of the nearby residents. But, as the permitted level of pollution is given, the expression of the residents's interim reservation utility is bounded from below, as in our model. Given quasi-linearity and the fact that he did not include in his model ex-post individual rationality constraints (as we do), Neeman (1999) obtains efficient outcomes, unlike us.

Finally, our paper is related to the sizable literature on fiscal federalism under asymmetric information. As we also do, this literature seeks to explain the properties of intergovernmental grants designed by a central government that does not know the preferences or production technologies of local jurisdictions. But our paper differs from this literature in two related aspects. This literature treats local public goods as continuous variables; whereas we consider a discrete noxious facility undertaken by the central government, not by the local authority. Under this circumstance, the prerogatives of the central government with respect to the project construction's decision and to the transfers it can impose become a crucial element of the analysis. In this paper, the central government's prerogatives are limited, whereas the fiscal federalism literature adopts the same extreme assumptions that we mention in the Introduction. On the one hand, Cremer, Marchand and Pestieau (1996), Raff and Wilson (1997), Cremer and Pestieau (1997), Bucovetsky, Marchand and Pestieau (1998) and Bordignon, Manasse and Tabellini (2001) do not limit the prerogatives of the central government. On the other hand, Lockwood (1999), Cornes and Silva (2000, 2002) and Besfamille (2003) impose participation constraints on the design of intergovernmental grants. In Lockwood (1999) and Besfamille (2003), these constraints never bind at the optimum. Although in Cornes and Silva (2000, 2002) these constraints may bind, a careful examination of these two articles reveals differences with respect to our paper. In their first article, the authors impose ex-ante participation constraints; not ex-post, as we do. In their second article, they do consider ex-post participation constraints. Nevertheless, to characterize the parameter conditions under which these constraints bind, in the Appendix of their

\footnotetext{
${ }^{14} \mathrm{He}$ only discusses the relaxation of this assumption informally, in the last section of his article.
} 
article they normalize the outside option to 0 . So their analysis is less general than ours. Therefore, neither of these articles raises the issue about the power and the prerogatives of the central government in federations, in situations of asymmetric information, with the generality as we do.

\section{Conclusion}

The construction of noxious facilities is a policy area where it is evident that jurisdictional authorities have limited prerogatives. The goal of this paper was to incorporate these limited prerogatives in a model solved with a mechanism design approach. We formalized a country consisting of two regions, each ruled by a local authority. The central government should decide whether to construct a noxious facility in one of the regions and how to finance it. If it is constructed, this facility causes a damage in the host region but generates a benefit in the other one.

The central government does not observe the damage because it is in fact private information of the host region. To deal with this informational gap, the central government designs an incentive-compatible mechanism, specifying if the noxious facility should be undertaken and a balanced scheme of interregional transfers. In its choice, the central government is constitutionally constrained to respect a given level of minimal welfare in both regions.

In this very simple model, we have completely characterized the optimal allocations under asymmetric information. We have explained how different constitutional constraints impact these allocations, specially the distortions that appear in the decision about which noxious facility is constructed and in the transfers imposed. We also show that, provided the central government has the power to do so, it is optimal to tax the host region when the noxious facility should not be undertaken. Therefore, adopting more realistic assumptions of limited prerogatives implies that it is necessary to discuss about the restrictions on transfers that the central government can impose to both regions.

This model can be extended in many different directions. First of all, we can consider multidimensional asymmetric information to analyze the localization of the noxious facility. Second, the result that the host region should be taxed when the noxious facility is not constructed raises the issue about the ability of the central government to commit to this policy. Relaxing the full-commitment assumption seems also a promising venue for future research. Finally, a third direction could be to use this model as a first step towards the endogenization of the constitutional setting. We could obtain some insights concerning constitutional design for rising federations, which could serve in political discussion, for example at the European level. 


\section{Appendix}

\section{Optimal allocations under full information}

When the central government observes $b$ and $d$, optimal transfers verify $\sum_{i} t_{i}^{1}=c$ and $t_{i}^{0}=0$. Conditional on the noxious facility being constructed, the central government solves the following problem

$$
\mathcal{P}^{*} \begin{cases}\underset{t_{H}, t_{R}}{\operatorname{Max}} u\left(\omega-t_{H}\right)-d+u\left(\omega-t_{R}\right)+b \\ \text { subject to } \\ u\left(\omega-t_{H}\right)-d \geq k \quad\left(C C_{H}\right) \\ t_{H}+t_{R}=c\end{cases}
$$

where $\left(C C_{H}\right)$ is the pertinent constitutional constraint and $(B)$, the central government's budget constraint. From $(B)$, we obtain $t_{R}$ and replace it in the objective. Therefore, we can write the Lagrangian of this problem as follows

$$
\mathcal{L}=u\left(\omega-t_{H}\right)-d+u\left(\omega-c+t_{H}\right)+b-\lambda\left[k-u\left(\omega-t_{H}\right)+d\right]
$$

where $\lambda$ is the Lagrange multiplier associated to $\left(C C_{H}\right)$. The first-order condition that characterizes the optimal transfer $t_{H}^{*}$ is

$$
\frac{\partial \mathcal{L}}{\partial t_{H}}=u^{\prime}\left(\omega-t_{R}\right)-(1+\lambda) u^{\prime}\left(\omega-t_{H}\right)=0
$$

Two possible cases can emerge.

First, if $\left(C C_{H}\right)$ does not bind, $\lambda=0$. So, by inspection of (1), optimal transfers verify $t_{H}^{*}=t_{R}^{*}=c / 2$. The value of the damage above which the noxious facility is optimally constructed is given by

$$
d^{*}=b-2[u(\omega)-u(\omega-c / 2)]
$$

Graphically, this is a line that increases with $b$.

Second, if $\left(C C_{H}\right)$ binds, the optimal transfer is simply given by this binding constraint and thus $t_{H}^{*}=\omega-u^{-1}(k+d)$. The value of the damage above which the noxious facility is optimally constructed, in this second case, is implicitly given by

$$
2 u(\omega)=k+u\left(2 \omega-c-u^{-1}(k+d)\right)+b
$$

Applying the Implicit Function theorem to (2), we can show that this particular value of the damage is an increasing and concave function of $b$.

Finally we find the parametric conditions such that $\left(C C_{H}\right)$ binds. These can be obtained when $\lambda=0$ (and thus $t_{H}^{*}=t_{R}^{*}=c / 2$ ) and $u\left(\omega-t_{H}\right)-d=k$. Hence, the value of the damage above which $\left(C C_{H}\right)$ binds equals $u(\omega-c / 2)-k$. With all this information, we can draw Figures 1(a) and 1(b) that appear in the text 


\section{Proof of Lemma 1}

1. If $\delta(d)=\delta\left(d^{\prime}\right)=1$, by $\left(I C_{H}\right)$ we have

$$
\begin{aligned}
& u\left(\omega-t_{H}^{1}(d)\right)-d \geq u\left(\omega-t_{H}^{1}\left(d^{\prime}\right)\right)-d \\
& u\left(\omega-t_{H}^{1}\left(d^{\prime}\right)\right)-d^{\prime} \geq u\left(\omega-t_{H}^{1}(d)\right)-d^{\prime}
\end{aligned}
$$

These two inequalities imply $u\left(\omega-t_{H}^{1}(d)\right)=u\left(\omega-t_{H}^{1}\left(d^{\prime}\right)\right)$, which proves that $t_{H}^{1}(d)=$ $t_{H}^{1}\left(d^{\prime}\right)$.

Again, if $\delta(d)=\delta\left(d^{\prime}\right)=0$, by $\left(I C_{H}\right)$ we have

$$
\begin{aligned}
& u\left(\omega-t_{H}^{0}(d)\right) \geq u\left(\omega-t_{H}^{0}\left(d^{\prime}\right)\right) \\
& u\left(\omega-t_{H}^{0}\left(d^{\prime}\right)\right) \geq u\left(\omega-t_{H}^{0}(d)\right)
\end{aligned}
$$

These two inequalities imply $u\left(\omega-t_{H}^{0}(d)\right)=u\left(\omega-t_{H}^{0}\left(d^{\prime}\right)\right)$, which proves that $t_{H}^{0}(d)=$ $t_{H}^{0}\left(d^{\prime}\right)$.

From now on, let $t_{i}^{1}(d)=t_{i}^{1}$ and $t_{i}^{0}(d)=t_{i}^{0}$ denote transfers when the noxious facility is constructed and not constructed, respectively.

2. Let $d<d^{\prime}$ and assume that $\delta(d)=0<\delta\left(d^{\prime}\right)=1$. By $\left(I C_{H}\right)$ we have

$$
\begin{aligned}
& u\left(\omega-t_{H}^{1}\right)-d^{\prime} \geq u\left(\omega-t_{H}^{0}\right) \\
& u\left(\omega-t_{H}^{0}\right) \geq u\left(\omega-t_{H}^{1}\right)-d
\end{aligned}
$$

These two inequalities imply $d-d^{\prime} \geq 0$, which is a contradiction. Hence $\delta(d) \geq \delta\left(d^{\prime}\right)$.

3. The existence of the threshold $\widehat{d}$ is ensured by the parametric assumptions of the model (i.e. $D>>d^{*}$ for $k \rightarrow-\infty$ ). The uniqueness of $\widehat{d}$ is an immediate consequence of Part 2 of this lemma.

4. Assume first that, at the optimum, $t_{H}^{1}+t_{R}^{1}>c$. The central government can always reduce $t_{R}^{1}$. This change does not alter the incentive properties of the mechanism, relaxes $\left(C C_{H}\right)$ and increases the expected welfare, which is a contradiction. So, at the optimum, $t_{H}^{1}+t_{R}^{1}=c$.

Next assume that, at the optimum, $t_{H}^{0}+t_{R}^{0}>0$. The central government can always reduce $t_{R}^{0}$. This change does not alter the incentive properties of the mechanism, relaxes $\left(C C_{R}\right)$ and increases the expected welfare, which is again a contradiction. So, at the optimum, $t_{H}^{0}+t_{R}^{0}=0$.

5. By $\left(I C_{H}\right), u\left(\omega-t_{H}^{1}(d)\right)-d \geq u\left(\omega-t_{H}^{0}\left(d^{\prime}\right)\right)$ if $\delta(d)=1$ and $\delta\left(d^{\prime}\right)=0$. Also by $\left(C C_{H}\right), u\left(\omega-t_{H}^{0}\left(d^{\prime}\right)\right) \geq k$. Hence $u\left(\omega-t_{H}^{1}(d)\right)-d \geq k$ holds 


\section{Proof of Proposition 1}

Using Lemma 1, the problem $\mathcal{P}$ boils down to the reduced problem $\mathcal{P}^{\prime}$

$$
\mathcal{P}^{\prime} \begin{cases}\underset{\widehat{d}, t_{H}^{1}, t_{H}^{0}, t_{R}^{1}}{\operatorname{Max}} \int_{0}^{\widehat{d}}\left[u\left(\omega-t_{H}^{1}\right)+u\left(\omega-t_{R}^{1}\right)+(b-d)\right] d F(d) \\ \\ \quad+\int_{\widehat{d}}^{D}\left[u\left(\omega-t_{H}^{0}\right)+u\left(\omega+t_{H}^{0}\right)\right] d F(d) \\ \text { subject to } \\ u\left(\omega-t_{H}^{0}\right) \geq k \\ u\left(\omega-t_{H}^{1}\right)-\widehat{d} \geq u\left(\omega-t_{H}^{0}\right) & \left(\lambda_{2}\right) \\ t_{H}^{1}+t_{R}^{1}=c & \left(\lambda_{3}\right)\end{cases}
$$

where $\lambda_{1}, \lambda_{2}, \lambda_{3}$ are usual Lagrange multipliers. For the moment, we have neglected three constraints; then we will show that they hold at the optimum. The set of incentive-compatibility constraints $\left(I C_{H}\right)$ has been replaced by a unique constraint, the one that characterizes the region $H$ with damage $\widehat{d}$, which is the highest damage for which the noxious facility is constructed. If we denote by $\mathcal{L}$ the Lagrangian of this problem $\mathcal{P}^{\prime}$, the first-order conditions can be written as follows

$$
\begin{aligned}
& \frac{\partial \mathcal{L}}{\partial t_{H}^{1}}=-\int_{0}^{\widehat{d}} u^{\prime}\left(\omega-t_{H}^{1}\right) d F(d)-\lambda_{2} u^{\prime}\left(\omega-t_{H}^{1}\right)+\lambda_{3}=0 \\
& \frac{\partial \mathcal{L}}{\partial t_{R}^{1}}=-\int_{0}^{\widehat{d}} u^{\prime}\left(\omega-t_{R}^{1}\right) d F(d)+\lambda_{3}=0 \\
& \frac{\partial \mathcal{L}}{\partial t_{H}^{0}}=-\int_{\widehat{d}}^{D}\left[u^{\prime}\left(\omega-t_{H}^{0}\right)-u^{\prime}\left(\omega+t_{H}^{0}\right)\right] d F(d)+\left(\lambda_{2}-\lambda_{1}\right) u^{\prime}\left(\omega-t_{H}^{0}\right)=0 \\
& \frac{\partial \mathcal{L}}{\partial \widehat{d}}=\left[u\left(\omega-t_{H}^{1}\right)-\widehat{d}+u\left(\omega-t_{R}^{1}\right)+b-u\left(\omega-t_{H}^{0}\right)-u\left(\omega+t_{H}^{0}\right)\right] f(\widehat{d})-\lambda_{2}=0
\end{aligned}
$$

The following lemmas prove proposition 1.

Lemma 2 At the optimum, $\lambda_{2}>0$.

Proof. We prove this by contradiction. Assume that $\lambda_{2}=0$ at the optimum. Substituting $\lambda_{2}=0$ in (5) gives $\partial \mathcal{L} / \partial t_{H}^{0}<0$ for any $t_{H}^{0}>0$, so that $t_{H}^{0}=0$. Moreover, combining (3) and (4), we obtain $t_{H}^{1}=t_{R}^{1}=c / 2$. This implies that $u\left(\omega-t_{H}^{1}\right)-\widehat{d}-u\left(\omega-t_{H}^{0}\right)=u(\omega-c / 2)-$ $\hat{d}-u(\omega)<0$ which violates the incentive-compatibility constraint, a contradiction. So $\lambda_{2}>0$ 
Lemma 3 When $k=u(\omega), t_{H}^{0}=0$; while for any $k<u(\omega), t_{H}^{0}>0$.

Proof. For $k=u(\omega)$, it is clear that $t_{H}^{0}$ cannot be positive otherwise the constitutional constraint is not fulfilled. Now consider the case where $k<u(\omega)$. If $\lambda_{1}=0$, (5) gives

$$
(1-F(\hat{d}))\left[u^{\prime}\left(\omega-t_{H}^{0}\right)-u^{\prime}\left(\omega+t_{H}^{0}\right)\right]=\lambda_{2} u^{\prime}\left(\omega-t_{H}^{0}\right)
$$

Since $\lambda_{2}>0,(7)$ implies $u^{\prime}\left(\omega-t_{H}^{0}\right)>u^{\prime}\left(\omega+t_{H}^{0}\right)$ so necessarily $\widehat{t}_{H}^{0}>0$ by concavity of the utility function $u\left(\right.$ ). If $\lambda_{1}>0, u\left(\omega-t_{H}^{0}\right)=k<u(\omega)$ so $t_{H}^{0}>0$

Lemma 4 There exists a threshold $\widehat{k}$ such that $\lambda_{1}>0$ for $k \geq \widehat{k}$ and $\lambda_{1}=0$, for $k<\widehat{k}$.

Proof. Suppose that $\lambda_{1}=0$. Then for any $k<u(\omega), t_{H}^{0}>0$ by Lemma 3 and is implicitly determined by (7) where $\lambda_{2}$ and $\widehat{d}$ are determined independently of $k$. Thus there exists $\widehat{k}<u(\omega)$ such that $u\left(\omega-t_{H}^{0}\right)=k$. Thus, for any $k<\widehat{k}, \lambda_{2}=0$; whereas for any $k \geq \widehat{k}$, $u\left(\omega-t_{H}^{0}\right)<k$ so that $\lambda_{2}>0$ and the optimal solution yields $u\left(\omega-t_{H}^{0}\right)=k$

Lemma 5 For any $k<\widehat{k}, \widehat{d}$ is independent of $k$; whereas for $k \geq \widehat{k} d \widehat{d} / d k<0$.

Proof. When $k<\widehat{k}, \lambda_{1}=0$ by Lemma 4 . First order conditions (3) to (6) and binding constraints do not depend on $k$. When $k \geq \widehat{k}, \lambda_{1}>0$. Rearranging the first order conditions (6) with (3) to (5), one has

$$
\frac{\partial \mathcal{L}}{\partial \widehat{d}}=\left[u\left(\omega-t_{R}^{1}\right)+b-u\left(\omega+t_{H}^{0}\right)\right]+\frac{F(\widehat{d})}{f(\widehat{d})}\left[1-\frac{u^{\prime}\left(\omega-t_{R}^{1}\right)}{u^{\prime}\left(\omega-t_{H}^{1}\right)}\right]=0
$$

where

$$
\begin{aligned}
& u\left(\omega-t_{H}^{0}\right)=k \\
& u\left(\omega-t_{H}^{1}\right)-\widehat{d}=u\left(\omega-t_{H}^{0}\right)
\end{aligned}
$$

(9) and (10) define $t_{H}^{0} \equiv t_{H}^{0}(k)$ with $d t_{H}^{0} / d k=-1 / u^{\prime}\left(\omega-t_{H}^{0}\right)$ and $t_{H}^{1} \equiv t_{H}^{1}(k, \widehat{d})$ with $d t_{H}^{1} / d k=d t_{H}^{1} / d \widehat{d}=-1 / u^{\prime}\left(\omega-t_{H}^{1}\right)$. Hence one can rewrite (8) as

$$
\begin{aligned}
& \frac{\partial \mathcal{L}}{\partial \widehat{d}} \equiv \phi(\widehat{d}, k)=\left[u\left(\omega-c+t_{H}^{1}(k, \widehat{d})\right)+b-u\left(\omega+t_{H}^{0}(k)\right)\right]+ \\
& \frac{F(\widehat{d})}{f(\widehat{d})}\left[1-\frac{u^{\prime}\left(\omega-c+t_{H}^{1}(k, \widehat{d})\right)}{u^{\prime}\left(\omega-t_{H}^{1}(k, \widehat{d})\right)}\right]=0
\end{aligned}
$$

and compute $d \widehat{d} / d k=-(\partial \phi / \partial k) /(\partial \phi / \partial \widehat{d})$ where $\partial \phi / \partial \widehat{d}<0$ because of the second-order condition. Thus

$$
\operatorname{sign}\left(\frac{d \widehat{d}}{d k}\right)=\operatorname{sign}\left(\frac{\partial \phi}{\partial k}\right)
$$


Differentiation of the RHS of (11) with respect to $k$ gives

$$
\begin{aligned}
\frac{\partial \phi}{\partial k}= & -\frac{u^{\prime}\left(\omega-t_{R}^{1}\right)}{u^{\prime}\left(\omega-t_{H}^{1}\right)}+\frac{u^{\prime}\left(\omega+t_{H}^{0}\right)}{u^{\prime}\left(\omega-t_{H}^{0}\right)}- \\
& \frac{F(\widehat{d})}{f(\widehat{d})\left[u^{\prime}\left(\omega-t_{R}^{1}\right)\right]^{2}}\left[-u^{\prime \prime}\left(\omega-t_{R}^{1}\right)-u^{\prime \prime}\left(\omega-t_{H}^{1}\right) \frac{u^{\prime}\left(\omega-t_{R}^{1}\right)}{u^{\prime}\left(\omega-t_{R}^{1}\right)}\right]
\end{aligned}
$$

where

$$
\frac{u^{\prime}\left(\omega+t_{H}^{0}\right)}{u^{\prime}\left(\omega-t_{H}^{0}\right)}-\frac{u^{\prime}\left(\omega-t_{R}^{1}\right)}{u^{\prime}\left(\omega-t_{H}^{1}\right)}<0
$$

since $t_{H}^{0}>0$ and $t_{R}^{1}>t_{H}^{1}$. The third term in the RHS is also negative, so $\partial \phi / \partial k<0$ implying that $d \widehat{d} / d k<0$

Lemma $6 \widehat{d}<d^{*}$.

Proof. The first term in brackets of (11) evaluated at the point $d^{*}(b, u(\omega))$ is equal to 0 . Thus, the first order condition defining $\widehat{d}$ evaluated at $d^{*}(b, u(\omega))$ is negative. By strict concavity of the objective function, this means that $\widehat{d}<d^{*}(b, u(\omega))$. But since $d^{*}(b, u(\omega))<$ $d(b, k)$ for any $k<u(\omega)$ (as shown in Section 2), one has $\widehat{d}<d^{*}(b, k)$

With all these results, it is straightforward to verify that the remaining three constraints hold. 


\section{References}

[1] Besfamille, M. (2004) "Local Public Works and Intergovernmental Transfers under Asymmetric Information", Journal of Public Economics, 88, 353-375.

[2] Bordignon, M., Manasse, P. and G. Tabellini (2001) "Optimal Regional Redistribution Under Asymmetric Information", American Economic Review, 91, 709-723.

[3] Bucovetsky, S., Marchand, M. and P. Pestieau (1998) "Tax Competition and Revelation of Preferences for Public Expenditure", Journal of Urban Economics, 44, 367-390.

[4] Cornes, R. and E. Silva (2000) "Local Public Goods, Risk Sharing, and Private Information in Federal Systems", Journal of Urban Economics, 47, 39-60.

[5] Cornes, R. and E. Silva (2002) "Local public goods, inter-regional transfers and private information", European Economic Review, 46, 329-356.

[6] Cremer, H., Marchand, M. and Pestieau, P. (1996) "Interregional Redistribution Through Tax Surcharge", International Tax and Public Finance, 3, 157-173.

[7] Cremer, H. and P. Pestieau (1997) "Income Redistribution in an Economic Union: The Trade Off Between Inter- and Intra-National Redistribution", International Tax and Public Finance, 4, 325-335.

[8] Crémer, J., Estache, A. and Seabright, P. (1995) "The Decentralization of Public Services: Lessons from the Theory of the Firm?" in A. Estache (ed.) Decentralizing Infrastructure: Advantages and Limitations, The World Bank, Washington DC.

[9] Darby, J. (1990) "Confiscatory Taxation", The American Journal of Comparative Law, 38, 545-555.

[10] Easterling, D. and Kunreuther, H. (1992) "Gaining Acceptance for Noxious Facilities with Economic Incentives" in Bromley, D. and Segerson, K. (Eds.) The Social Response to Environmental Risk, Kluwer Academic Publishers, London.

[11] Easterling, D. and Kunreuther, H. (1996) "The Role of Compensation in Siting Hazardous Facilities", Journal of Policy Analysis and Management, 15, 601-622.

[12] Goetze, D. (1982) "A decentralized mechanism for siting hazardous waste disposal facilities", Public Choice 39, 361-370.

[13] Gradstein, M. (1994) "Efficient provision of a discrete public good", International Economic Review 33, 877-897.

[14] Green, J. and Laffont, J.-J. (1979) Incentives in Public Decision Making, North-Holland. 
[15] Jean-Marie, A., N. Marchetti and M. Tidball (2004) "Low-bid auction versus high-bid auction for siting noxious facilities in a two-city region: an exact approach," Working Paper 2004s-52, CIRANO, Montreal.

[16] Kim, S. (2003) "An almost Ideal Solution to the Siting Problem of Publicly Provided Indivisible Goods," International Tax and Public Finance, 10, 357-375.

[17] Kleindorfer, P. and Kunreuther, H. (1986) "A Sealed-Bid Auction Mechanism for Siting Noxious Facilities", American Economic Review Papers and Proceedings, 76, 295-299.

[18] Kleindorfer, P. and M. Sertel (1994) "Auctioning the Provision of an Indivisible Public Good," Journal of Economic Theory, 64, 20-34.

[19] Klibanoff, P. and Morduch, J. (1995) "Decentralization, Externalities, and Efficiency", Review of Economic Studies, 62, 223-247.

[20] Ledyard and Palfrey (1994) "Voting and Lottery Drafts as Efficient Public Goods Mechanisms", Review of Economic Studies, 61, 327-355.

[21] Lescop, D. (2006) "Optimal Mechanisms for Siting Noxious Facilities," Review of Economic Design, forthcoming.

[22] Lockwood, B. (1999) "Inter-regional Insurance", Journal of Public Economics, 72, 1-37.

[23] Makowski, L. and Mezzetti, C. (1994) "Bayesian and Weakly Robust First Best Mechanisms: Characterizations ", Journal of Economic Theory, 64, 500-519.

[24] Minehart, D. and Z. Neeman (2002) "Effective Siting of Waste Treatment Facilities," Journal of Environmental Economics and Management, 43, 303-324.

[25] Neeman, Z. (1999) "Property Rights and Efficiency of Voluntary Bargaining under Asymmetric Information," Review of Economic Studies, 66, 679-691.

[26] O'Sullivan, A (1993) "Voluntary Auctions for Noxious Facilities: Incentives to Particiapte and the Efficiency of Siting Decisions," Journal of Environmental Economics and Management, 25, S12-S26.

[27] Pérez-Castrillo, D. and D. Wettstein (2002) "Choosing Wisely: A Multibidding Approach," American Economic Review, 92, 1577-1587.

[28] Raff, H. and J. Wilson (1997) "Income Redistribution with Well-Informed Local Governments", International Tax and Public Finance, 4, 407-427.

[29] Rob, R. (1989) "Pollution Claim Settlements under Private Information," Journal of Economic Theory, 47, 307-333.

[30] Samuelson, W. (1985) "A comment on the Coase theorem," in A. Roth (Ed.) GameTheoretic Models of Bargaining, Cambridge, Cambridge University Press. 
[31] Tideman, N. and G. Tullock (1976) "A New and Superior Process for Making Social Choices," Journal of Political Economy, 84, 1145-1159.

[32] Waehrer, K. (2003) "Hazardous Facility Siting When Cost Information is Private: An Application of Multidimensional Mechanism Design," Journal of Public Economic Theory, $\mathbf{5}, 605-622$.

[33] Wolsink, M. (1994) "Entanglement of Interests and Motives: Assumptions behind the NIMBY-theory on Facility Siting," Urban Studies, 6, 851-866. 


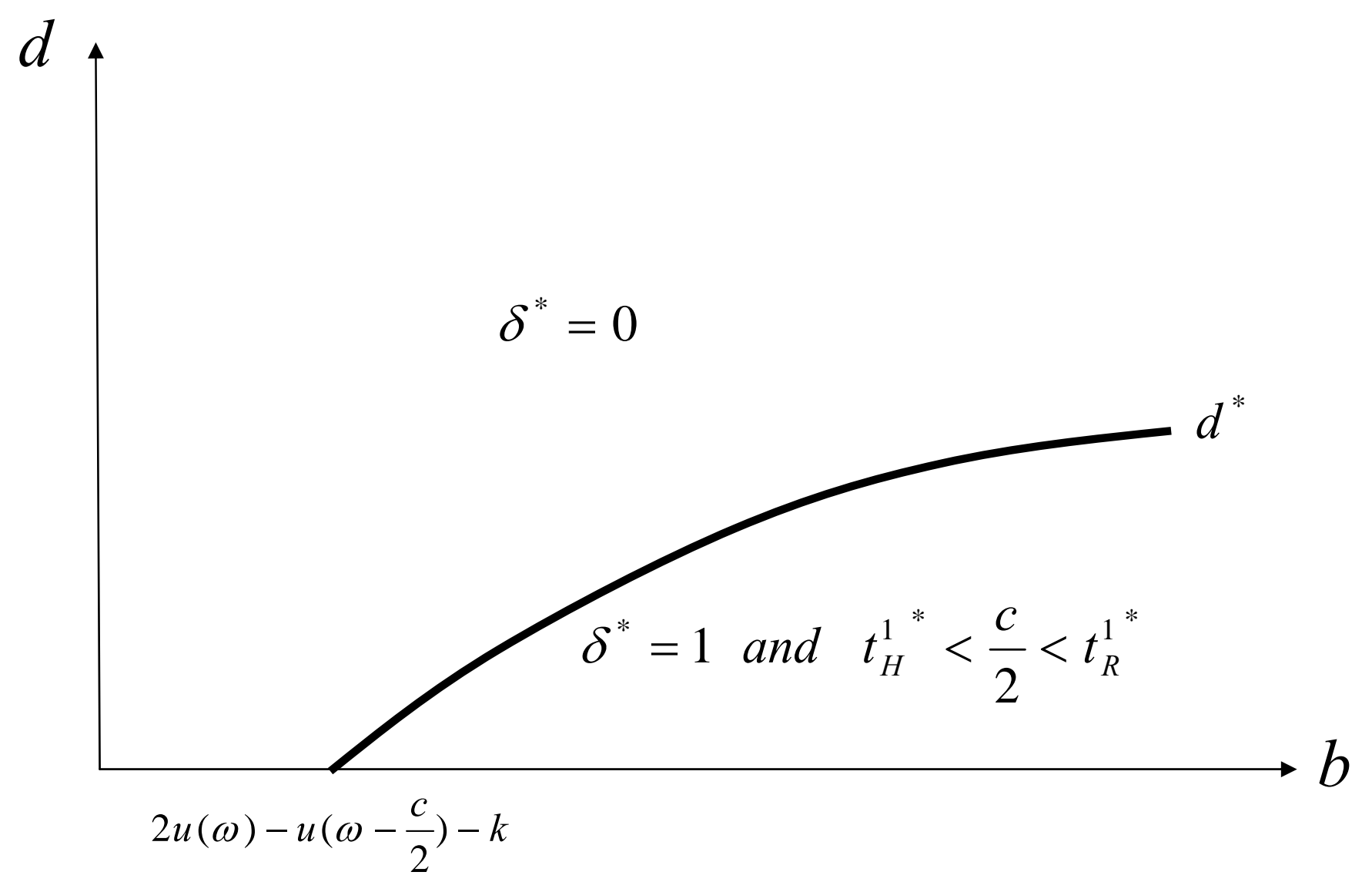

Figure 1(a): Optimal allocations when $k \geq u(\omega-c / 2)$ 


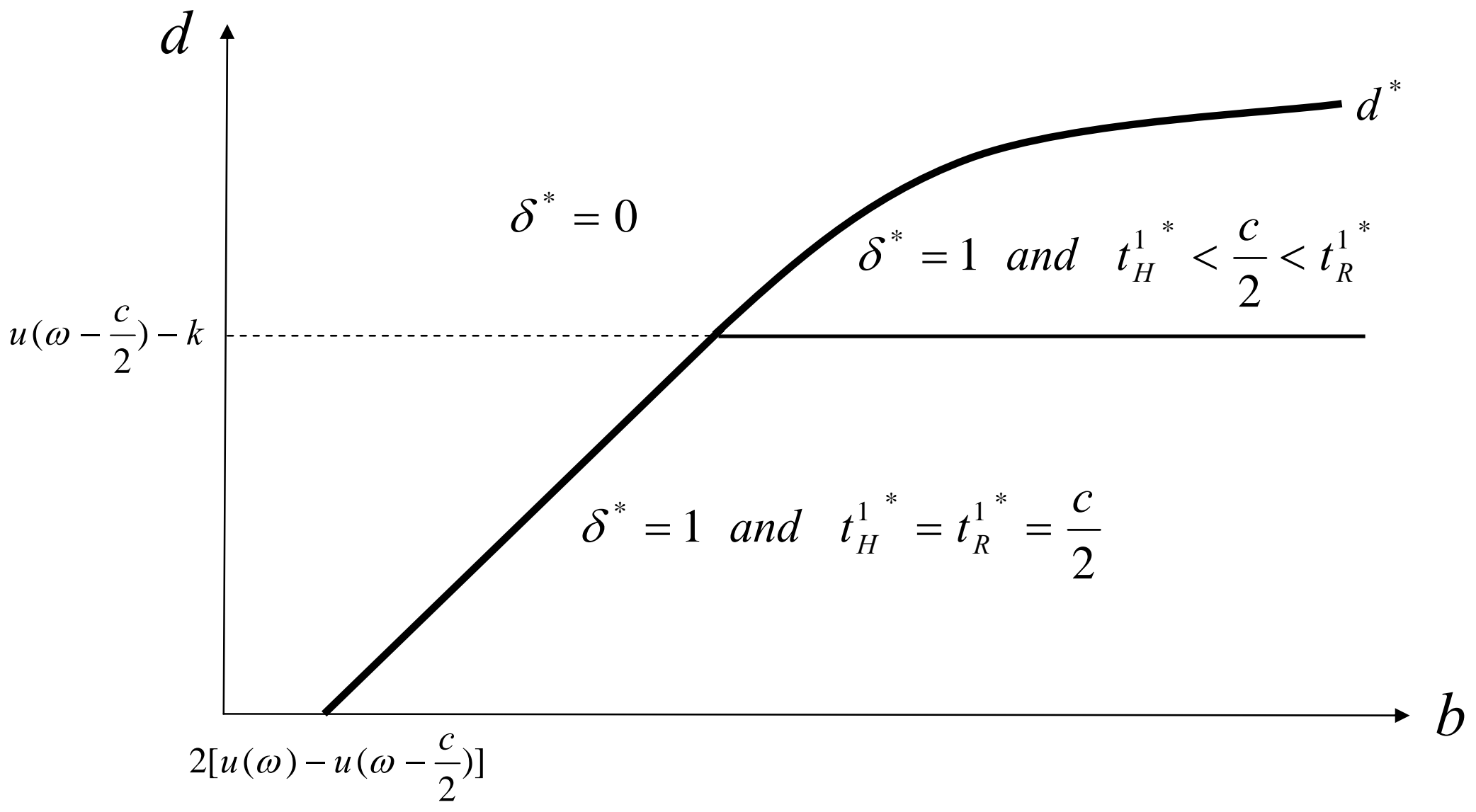

Figure 1(b): Optimal allocations when $k<u(\omega-c / 2)$ 